Conclusion: Today, in the twenty-first century, the increasingly popular question, come to us from ancient times: "Man is the measure of all things?!" On this occasion Director of the Institute of Life Maurice Marois already 30 years ago (1988) it was said: "Life has a great future, but with someone or without." And response to the words of the great scientist should give the perspectives of educational goals, objectives, technologies in full their understanding of all intelligent, educated mankind, every human person, the World!

\title{
Literature
}

1. Anisimov V. V., Grokholsky O. G., Nikandrov N. D. General principles of pedagogy: textbook for universities // Moscow: Prosveshchenie, 2006. 574 p.

2. Asmolov A. G. Psychology of personality. Cultural-historical understanding of human development. / M.: Academy, 2007. 423 p.

3. Boytsov S. A., Samorodskaya I. V., Tretyakov V. V. the Gradient of mortality of the population aged $40-59$ years in the subjects of the Russian Federation // Vestnik RAMN, 2014. No. 7-8. P. $106-111$.

4. Sackcloth E. V. the Basic categories of pedagogy: upbringing, education, culture // problems of modern education, 2010. No.

5. S. 19-29 5. Sommer D. S. How much is man? M: BOLEN, 2011. 191 p.

6. Erich D. Jarvis. A flock of genomes // Science, 2014. V. 346. P. 1320-1331.

7. D. Shambaugh, “China and Europe: The Emerging Axis”, Current History, September 2004, p. 243-249.

Gordienko Elena Nikolaevna - Professor, doctor of medical Sciences Department of histology and biology Of the "Amur state medical Academy". Gen-45@rambler.ru 8-924-6747-204. Russian Federation. Blagoveshchensk, Lenin str. 153

UDC 319-036.1 DOI 10.22448/AMJ.2017.3.151-152

\section{FIBROSING ALVEOLITI WITH SYSTEMIC SCROLLEROMY}

\author{
Goryacheva S.A., Voitsekhovsky V.V., Pogrebnaya M.V., Prikhodko O.B., Kostrova I.V.
}

Amur State Medical Academy, Blagoveshchensk, Russia

Summary: pulmonary involvement proceeds in SSD is caused by arterial damage and / or fibrosing process in the pulmonary parenchyma and in the form of two main syndromes rarely combined in one patient - pulmonary arterial hypertension (PAH) and interstitial lung lesions (IPL). [5 ]. The incidence of pulmonary pathology is high with SSD. Changes are found on chest radiographs in $45-56 \%$ of patients. We analyzed the frequency of lung injury in patients with chronic cardiovascular disease in the rheumatological department for five years. IPL identified only at $11.2 \%$. The case of Fibrozing alveolitis was presented in the onset of the disease with its late diagnosis as a demonstration.

Basic words: fibrosing alveolitis, systemic scleroderma.

The immune disorders are the basis of pathogenesis of systemic scleroderma (SSD), also a vasculopathy with severe microcirculation disorders and generalized fibrosis [2]. Lung damage affects adversely on the prognosis and ranks first among the causes of death with SSD. Pulmonary disorders are most often detected with the greatest frequency, with multispiral computed tomography (MSCT) of the chest - in $80 \%$ of cases [3]. Data from the literature indicate that the first years of the SSD are determinative in terms of the origin and development of viscerites in general and IPL in particular. It is known that the beginning of the fibrous process in the lungs in most patients falls on the first 4-6 years of the disease [4]

The aim of the work was to analyze the incidence of IPL in patients with SSD and the features of their course. Material and methods. We analyzed 39 case histories of patients with chronic obstructive pulmonary disease who were on treatment at the rheumatological department of the AOKB from 2012 to 2017. Among them, IPL were detected in five patients, which was $12.8 \%$. In four cases IPL diagnosed an average of 5 years in the course of the disease, and in one case it was the debut of the disease. As an example, we present a clinical case of lung injury, in the form of fibrosing alveolitis, which outstripped other manifestations of systemic scleroderma for several years. Patient K., 26 years old, cook, was transferred to the rheumatological department in February 2017 from the pulmonology department, where she had been observed for two years before. She complained of dyspnoea at rest, aggravated with insignificant physical load, dry cough, chilliness of the hands, discoloration of the distal sections of the hands to red and cyanotic color during excitement and low temperatures, rare choking when taking rough food, general weakness, decreased ability to work. From an anamnesis it is known that since 2012 she began to celebrate periodically a cough with the departure of scant sputum of light color, in 2013, during the fluorographic examination, signs of bilateral pneumofibrosis were revealed, blood leukocytosis was diagnosed, and a chronic bronchitis was diagnosed. In 2014, with repeated fluorographic examination, the previous changes were preserved, a pulmonologist at the place of residence diagnosed with cystic hypoplasia. In 2015 , with a gestation period of 2526 weeks, shortness of breath appeared during exercise. Deterioration from 37 weeks, when on the background of acute respiratory viral infection noted increased dyspnoea, cough, delivery was performed by caesarean section, postpartum MSCT of the thorax: CT scan can correspond to ELISA in the stage of "cellular lung" formation. To clarify the diagnosis and treatment transferred to the pulmonology department. Objectively: BH 22 in 1 min. When auscultation in the lower lateral thoracic parts of the right and left revealed bilateral crepitus. In blood tests revealed: acceleration of ESR up to $112 \mathrm{~mm} / \mathrm{h}$, leukocytosis-13,9×109, iron deficiency anemia of mild severity (Hb-92 g / I, 
Ayr-3,53x1012, serum iron-4.78 $\mu \mathrm{mol} / \mathrm{I})$, CRP-65.98 mg / I, cholesterol -6,79 mg / I. Bronchoscopy: bilateral diffuse atrophic endobronchitis, IV. Bronchoalveolar lavage: bronchial epithelium-18\%, macrophages-34\%; segments-42\%, lymphocytes-6\%. ECHO-KG: episodes of tachycardia. Increased stress on the right gastric check. Minor regurgitation of the TC. Additional trabeculae in the LV cavity. LV systolic function is preserved. The emission fraction is $65.6 \%$. Diastolic dysfunction of the prostate is impaired by the first type. There are no signs of LH. Spirogram: severe disturbances of VFL by mixed type (ZHEL-27\%, FVC-33\%, FEV1-29\%). The diagnosis is made: idiopathic pulmonary fibrosis, a chronic course with the formation of a "cellular lung". DN II. Prednisolone $50 \mathrm{mg} /$ day was prescribed, taken for 6 months, with a decrease in the dose of prednisolone began to note the deterioration of the state of health: increased dyspnea, cough with sputum smeary, chilliness, discoloration of the distal parts of the hands to red and cyanotic color roughness and low temperatures, a rare puffing with the reception of rough food, general weakness, disability. In February 2017, examined by a rheumatologist, due to the presence of fibrosing alveolitis, Raynaud's syndrome, sclerodactyly, esophagitis, systemic scleroderma was diagnosed and the patient was transferred to the rheumatology department. Pathogenetic pulse-therapy is prescribed: glucocorticosteroids and cyclophosphamide.

Conclusion: We detected a small percentage of IPL in patients with chronic obstructive pulmonary disease, which is different from the literature data and is probably associated with a low diagnosis of this lesion, due to the fact that not all patients undergo MSCT of the thorax. Conducting MSCT in patients with SSD allows not only to reveal the characteristic symptoms of IPL, but also to estimate the extent of the lesion and the stage of development of the pathological process in the lungs, for the timely treatment of IPL [1]. In this clinical observation, fibrosing alveolitis was the debut of systemic scleroderma, having outstripped the other clinical symptoms of the disease for several years, the course of the alveolitis had a progressive nature, there was a significant decrease in pulmonary volumes and a rise in fibrosis.

\title{
LITERATURE
}

1. Ananieva L.P. Interstitial lung injury associated with systolic scleroderma (progressive systemic sclerosis) // Scientific and Practical Rheumatology. 2017. №1. P.68-86.

2. Guseva N.G. Systemic scleroderma. In the book: Sigidin YA, Guseva NG, Ivanov MM.

3. Diffuse diseases of connective tissue. M .: Medicine. 2004. P. 341-357.

4. Steen V.D., Conte C., Owens G.R., Medsgar T.A. Jr. Severe restrictive lung disease in systemic sclerosis. Arthritis Rheumatology. 1994; 37: 1283-9.

5. Steen V.D., Medsger T.A. Changes in causes of death in systemic sclerosis, 1972-2002. Annals of the Rheumatic Diseases. 2007; 66: 940-4.

UDC 616.24-002.54 DOI 10.22448/AMJ.2017.3.152-153

\section{MORPHOLOGICAL CHARACTERISTICS OF CELLULAR COMPOSITION OF FOCUS LUNG LESIONS IN CHRONIC FIBRO- CAVERNOUS MULTIDRUG- RESISTANT TUBERCULOSIS}

\author{
Makarov I. Yu., Barabash R. A.
}

\author{
Amur state medical academy, Blagoveshchensk, Russia
}

SUMMARY We studied the histological specimens of 62 patients who died from fibrocavernous pulmonary tuberculosis with multidrug-resistant (28 patients), poly-resistant (18 patients) and sensitive strains of mycobacteria (16 patients).

A number of features have been revealed that indicate a rapid, progressive course of the destructive tuberculous process in the lungs, with the most significant morphological changes occurring in people with multiresistant forms of lesion. This process is characterized by more pronounced specific inflammatory changes in the lung tissue: the presence of granulomas with central caseous necrosis, granulomas containing Pirogov cells, long-lasting granulomas with proliferation of fibrous connective tissue around them, lymphoid cell clusters in fibrous tissue in the pericavitic zones, as well as a large the number of lymphoid cells in the granulation and fibrous layers of the cavity.

Key words: chronic fibrocavernous tuberculosis, pathomorphology, drug resistance, inflammation.

Introduction Asharp increase in the drug resistance (DR) structure due to the growth of multidrug resistance (MDR) is explained bytheextensivecirculation ofM.tuberculosis(MBT)strainsinthegeneticfamilyBeijing inthe Russian Federation [1] . The tuberculosis infection caused by such pathogen is distinguished by a severe course with the outcome in a chronic recurrentform, which is notsuited toanti-tuberculosischemotherapyand requires the use of surgicalmethods of treatment $[1,5]$.

Thecharacter ofmorphologicalchangesinthelungtissueis directlydependentontheseverity of themanifestationsofinflammatoryresponse, which isassociated with theseverity ofdisease, determinethenature, formandextentoftheprocess $[2,3,4]$.

Objective: to reveal the morphological features of tuberculous lesion in patients with chronic fibrocavernous MDR pulmonary tuberculosis on the basis of quantitative and qualitative analysis of detected cell formations.

Materials and methods: autopsy material covering 62 patients who died from fibrocavernous pulmonary tuberculosis in medical institutions of the Amur Region. The groups are divided according to the type of DR pathogen: group I - MDR (28 people), II group -18 people with poly-resistance and group III - 16 people with preserved 